\title{
INVENTARISASI TANAMAN OBAT UNTUK PENDERITA HIPERTENSI DAN DIABETES MELITUS DI DESA KAMBUNO KECAMATAN BULUKUMPA KABUPATEN BULUKUMBA
}

\author{
*)Herman \\ *)Akademi Farmasi Sandi Karsa Makassar \\ *)Program Studi D-III Farmasi Sandi Karsa Makassar
}

\begin{abstract}
ABSTRAK
Penelitian di Desa Ajubissue yang telah dilakukan pada bulan Januari - Februari 2018 tentang inventarisasi tanaman obat untuk penderita hipertensi dan diabetes melitus yang bertujuan untuk mengetahui berapa banyak masyarakat Desa Kambuno Kecamatan bulukumpa kabupaten Bulukumba menggunakan tanaman tradisional sebagai obat hipertensi dan diabetes melitus. Jenis penelitian jenis penelitian ini sifatnya deskriptif dengan pendekatan Penelitian lapangan (Field Research) serta Penelitian Kepustakaan (Library Research) melakukan pengumpulan data menggunakan instrumen kuesioner dengan sampel sebanyak 73 orang responden yang dipilih berdasarkan teknik Accidental Sampling. Hasil penelitian menunjukkan bahwa terdapat 16 jenis tanaman obat yang terdiri dari 15 famili yang digunakan sebagai obat anti hipertensi dan 13 jenis tanaman obat yang terdiri dari 12 famili yang digunakan sebagai obat anti diabetes oleh masyarakat tersebut. Jenis tanaman obat yang paling sering digunakan untuk mengobati penyakit hipertensi adalah daun avokad dan daun kersen, sedangkan untuk mengobati penyakit diabetes melitus adalah buah mahkota dewa dan daun sirsak, metode pengolahan tumbuhan obat tersebut yang paling banyak digunakan adalah direbus.
\end{abstract}

Kata kunci : Inventarisasi, Tanaman Obat, Anti Hipertensi, Anti Diabetes

\section{PENDAHULUAN}

\section{A. Latar Belakang}

Pentingnya pengetahuan tentang penyakit tidak menular dilatar belakangi dengan kecenderungan semakin meningkatnya prevalensi penyakit tidak menular dalam masyarakat, termasuk kalangan masyarakat Indonesia. Bangsa Indonesia yang sementara membangun dirinya dari suatu negara agraris yang sedang berkembang menuju masyarakat industri membawa kecendrungan baru dalam pola penyakit dalam masyarakat. Perubahan pola struktur masyarakat agraris ke masyarakat industri banyak memberi andil terhadap perubahan pola fertilitas, gaya hidup dan sosial ekonomi, yang pada giliriannya dapat memicu peningkatan penyakit tidak menular (Bustan, 2007).

Penyakit tidak menular saat ini menjadi penyebab utama kematian secara global. World Health Organization (WHO) pada tahun 2012 dalam profil statistik Indonesia secara resmi merilis 10 penyakit penyebab kematian paling tinggi di Indonesia adalah penyakit stroke $(21 \%)$, penyakit jantung isemik $(9 \%)$, diabetes melitus (7\%), tuberculosis pernapasan $(5 \%)$, hipertensi (4\%), Penyakit Pernapasan Khususnya Penyakit Paru Obstruktif Kronis (PPOK) (3\%), penyakit Liver (3\%), akibat kecelakaan lalu lintas (3\%), pneumonia atau radang paru-paru (3\%), diare $(3 \%)$ (WHO, 2012).
Berdasarkan data yang diperoleh dari Dinas Kesehatan Kota Makassar adapun 10 (sepuluh) jenis penyakit penyebab utama kematian di Kota Makassar tahun 2015 adalah asma sebanyak 1.210 jiwa, jantung sebanyak 393 jiwa, hipertensi sebanyak 370 jiwa, diabetes melitus sebanyak 191 jiwa, stroke sebanyak 151 jiwa, maag sebanyak 151 jiwa, PPOK sebanyak 122 jiwa, kecelakaan sebanyak 76 jiwa, ginjal sebanyak 61 jiwa dan TB paru sebanyak 57jiwa (Dinkes Makassar, 2016).

Berdasarkan hasil Riset Kesehatan tahun 2013 prevalensi hipertensi pada penduduk umur 18 tahun ke atas di Indonesia adalah sebesar $31,7 \%$. Prevalensi penyakit hipertensi di Sulawesi Selatan 29,0\%, lebih rendah dari angka nasional. Menurut Kabupaten prevalensi hipertensi urutan kedua adalah Sidenreng Rappang (23,3\%) (Riskesdas, 2007).

Salah satu kota yang banyak terdapat tumbuhan obat adalah Kabupaten Bulukumba di Provinsi Sulawesi Selatan. Kabupaten Bulukumba khususnya di Kecamatan Bulukumpa, Desa Kambuno merupakan salah satu daerah yang masyarakatnya masih menjaga tradisi leluhur dengan memanfaatkan tumbuhan sebagai obat untuk mengobati suatu penyakit yang telah dikenal masyarakat sejak dulu hingga sekarang.

Dari tinjauan tersebut tersebut, penelitian ini bertujuan melihat penggunaan inventarisasi tanaman obat tradisional untuk penderita hipertensi dan diabetes melitus di Desa 
Kambuno Kecamatan Bulukumpa Kabupaten Kabupaten Bulukumba di wilayah Provinsi Sulawesi Selatan

\section{B. Rumusan Masalah}

1. Berapa banyak penggunaan tanaman obat untuk penderita hipertensi dan diabetes melitus yang digunakan oleh masyarakat Desa Kambuno Kecamatan Bulukumpa Kabupaten Bulukumba?

2. Tanaman obat apakah yang sering digunakan oleh penderita hipertensi dan diabetes melitus yang digunakan di Desa Kambuno Kaupaten Bulukumba?

\section{Tujuan Penelitian}

1. Tujuan Umum

Untuk melihat penggunaan inventarisasi tanaman obat tradisional untuk penderita hipertensi dan diabetes melitus di Desa Kambuno Kecamatan Bulukumpa Kabupaten Kabupaten Bulukumba di wilayah Provinsi Sulawesi Selatan

2. Tujuan Khusus

a. Menggali potensi dan informasi masyarakat di Desa Kambuna Kecamatan Bulukumpa Kabupaten Bulukumba tentang pemanfaatan jenis dan bagianbagin tanaman obat serta cara pengolahan tanaman obat untuk penderita hipertensi

b. Menggali potensi dan informasi masyarakat di Desa Kambuna Kecamatan Bulukumpa Kabupaten Bulukumba tentang pemanfaatan jenis dan bagianbagian tanaman obat serta cara pengolahan tanaman obat untuk penderita diabetes melitus.

\section{Manfaat Penelitian}

1. Manfaat Ilmiah

Dapat dijadikan sebagai referensi tambahan pustaka untuk memperkaya kajian pengobatan herbal, khususnya inventarisasi tanaman obat tradisional untuk penderita hipertensi dan diabetes melitus.

2. Manfaat Institusi

Hasil penelitian ini kiranya dapat dipergunakan sebagai salah satu pertimbangan dalam pengambilan kebijakan dan keputusan dalam mendukung programprogram instansi pemerintah dibidang kesehatan.

3. Manfaat Bagi Peneliti

a. Dapat dijadikan sebagai tambahan ilmu pengetahuan dan kepedulian tentang pengetahuan inventarisasi tanaman obat tradisional untuk penderita hipertensi dan diabetes melitus. b. Dapat dijadikan sebagai dasar untuk pengembangan penelitian lebih lanjut tentang inventarisasi tanaman obat tradisional untuk penderita hipertensi dan diabetes melitus di lingkungan masyarakat setempat.

\section{METODE PENELITIAN}

\section{A. Jenis Penelitian}

Metode penelitian yang digunakan dalam penelitian ini adalah deskriptif. Metode penelitian deskriptif adalah suatu metode penelitian yang dilakukan dengan tujuan utama membuat gambaran atau deskripsi tentang suatu keadaan secara objektif (Notoadmodjo, 2010).

\section{B. Waktu Dan Tempat Penelitian}

Penelitian ini dilakukan di Desa Kambuna Kecamatan Bulukumpa Kabupaten Bulukumba dengan pengambilan data akan dilaksanakan pada bulan Januari - Februari 2018.

\section{Populasi dan Teknik Penerikan Sampel}

a. Pupulasi dan Sampel

Populasi adalah keseluruhan objek penelitian atau objek yang diteliti (Notoatmodjo,2010). Populasi dalam penelitian ini adalah masyarakat Desa Kambuno Kecamatan Bulukumpa Kabupaten Bulukumba.

Sampel merupakan obyek yang diteliti yang dianggap mewakili seluruh populasi (Notoatmodjo, 2010). Adapun jumlah sampel sebanyak 269 kepala keluarga.

b. Teknik Penarikan Sampel

1. Besar Sampel

Jumlah sampel sebanyak 269 kepala keluarga.

2. Teknik Penentuan Sampel

Penentuan sampel dilakuakan dengan Accidental Sampling adalah Accidental Sampling (Supardi, 2014).

Pengambilan sampel dengan menggunakan rumus yang dikemukan Notoatmodjo, yaitu:

$$
\mathrm{n}=\mathrm{N} /\left(\mathrm{N} \cdot \mathrm{d}^{\wedge} 2+1\right)
$$

Keterangan:

$\mathrm{n}=$ besar sampel

$\mathrm{N}=$ besar populasi

$\mathrm{d}=$ level signifikan yang diinginkan (umumnya 0,05 untuk bidang non eksak dan 0,10 untuk bidang eksakta)

Adapun penentuan sampel mengambil presisi ditetapkan sebesar $10 \%$ 
dengan tingkat kepercayaan 90\%, maka ukuran sampelnya dapat ditetapkan sebagai beikut:

$$
\begin{aligned}
& \mathrm{n}=269 /\left(269 \llbracket(0,10) \rrbracket^{\wedge} 2+1\right) \\
& \mathrm{n}=269 /(269(0,01)+1) \\
& \mathrm{n}=269 /(2,69+1) \\
& \mathrm{n}=269 / 3,69 \\
& \mathrm{n}=72,8 \approx 73
\end{aligned}
$$

Adapun kriteria sampel, berdasar kriteria inklusi dan eksklusi, yaitu :

1) Kriteria Inklusi

a. Masyarakat yang berusia 17 tahun ke atas

b. Pernah menggunakan obat tradisional sebagai obat hipertensi dan diabetes mellitus

c. Bersedia diwawancarai

d. Tidak mengalami gangguan kejiwaan

2) Kriteria Ekslusi: Masyarakat yang tidak bersedia menjadi responden

\section{Pengumpulan dan Pengolahan Data}

1. Pengumpulan Data

a. Data Primer

Penelitian lapangan (Field Research), yakni berupa kuesioner untuk mengetahui gambaran yang nyata mengenai pengetahuan masyarakat tentang penggunaan obat tradisional sebagai obat hipertensi dan diabetes mellitus.

b. Data Sekundaer

Penelitian kepustakaan (Library Research), yakni menggunakan bukubuku yang berhubungan dengan masalah masalah yang dihadapi)

2. Pengolahan data

Proses pengelolaan data dalam penelitian ini dapat menggunakan perangkat lunak Komputer yaitu SPSS 21, dengan tahapan sebagai berikut :

a. Editing Data yaitu mengoreksi jawaban yang telah diberikan Responden, apabila ada data yang salah atau kurang segera dilengkapi.

b. Coding Data yaitu melakukan pengkodean terhadap beberapa variabel yang akan diteliti, dengan tujuan untuk mempermudah pada saat melakukan analisis data dan juga mempercepat pada saat entry data.

c. Entry Data yaitu memasukkan data dalam variabel sheet dengan menggunakan computer.

d. Cleaning Data yaitu pembersihan data untuk mencegah kesalahan yang mungkin terjadi, dalam hal ini tidak ikut sertakan nilai hilang (Missing Value) dalam analisis dan data yang tidak sesuai atau diluar range penelitian tidak diikutsertakan dalam analisis (Sumantri, 2011).

\section{HASIL PENELITIAN DAN PEMBAHASAN}

\section{A. Hasil Penelitian}

Pengumpulan data hasil penelitian yang dilakukan di Desa Kambuno Kecamatan Bulukumpa Kabupaten Bulukumba yang dilaksanakan pada bulan Mei-Juni 2018 dengan jumlah responden 73 orang, diperoleh 16 jenis tanaman hasil wawancara tentang tanaman obat pilihan masyarakat yang digunakan sebagai obat antihipertensi dan 13 jenis tanaman hasil wawancara tentang tanaman obat pilihan masyarakat yang digunakan sebagai obat antidiabetes melitus.

Tabel I. Karakteristik Responden berdasarkan Jenis Kelamin

\begin{tabular}{ccc}
\hline No & Jenis Kelamin & Jumlah (Responden) \\
\hline $\mathbf{1}$ & Laki-laki & 27 \\
\hline $\mathbf{2}$ & Perempuan & 46 \\
\hline \multicolumn{3}{c}{ Sumber : Data Primer, 2020 }
\end{tabular}

Tabel I menunjukkan sampel yang diambil sebanyak 73 responden yang terdiri dari jenis kelamin laki-laki sebanyak 27 orang responden sedangkan perempuan sebanyak 46 orang responden.

Tabel II. Karakteristik Responden berdasarkan Pendidikan

\begin{tabular}{ccc}
\hline No & $\begin{array}{c}\text { Pendidikn } \\
\text { terakhir }\end{array}$ & $\begin{array}{c}\text { Jumlah } \\
\text { Responden }\end{array}$ \\
\hline $\mathbf{1}$ & Tidak sekolah & 10 \\
\hline $\mathbf{2}$ & SD & 17 \\
\hline $\mathbf{3}$ & SMP & 13 \\
\hline $\mathbf{4}$ & SMA & 25 \\
\hline $\mathbf{5}$ & $\begin{array}{c}\text { Perguruan } \\
\text { tinggi }\end{array}$ & 8 \\
& Jumlah & 73 \\
\hline
\end{tabular}

Tabel II menunjukkan bahwa tingkat pendidikan 73 respoden masyarakat Desa Kambuno Kacamatan Bulukumpa Kabupaten Bulukumba yang menjadi sampel penelitian ini terdiri dari yang tidak memiliki pendidikan sampai perguruan tinggi, yaitu tidak sekolah sebanyak 10 responden, SD Sebanyak 17 responden, SMP 1 responden, SMA 25 responden dan perguruan tinggi sebanyak 8 responden. 
Tabel III. Karakteristik Responden berdasarkan Pekerjaan

\begin{tabular}{ccc}
\hline No & Pekerjaan & Jumlah Responden \\
\hline $\mathbf{1}$ & Petani & 47 \\
\hline $\mathbf{2}$ & PNS & 18 \\
\hline $\mathbf{3}$ & Mahasiswa & 8 \\
\hline \multicolumn{2}{c}{ Jumlah } & 73 \\
\hline
\end{tabular}

Sumber : Data Primer, 2020

Table III Menunjukkan bahwa pekerjaan dari 73 responden masyarakat adalah petani sebanyak 47 responden, PNS sebanyak18 responden dan mahasiswa sebanyak 8 responden.

Tabel IV. Daftar jenis tanaman dan metode pengolahan yang digunakan sebagai obat antihipertensi oleh masyarakat Desa Kambuno Kecamatan Bulukumpa Kabupaten Bulukumba

\begin{tabular}{|c|c|c|c|c|}
\hline No & $\begin{array}{c}\text { Nama } \\
\text { Tumbuhan }\end{array}$ & Nama Asal & $\begin{array}{c}\text { Frekuensi } \\
\text { Penggunaan }\end{array}$ & $\begin{array}{c}\text { Metode } \\
\text { Pengolahan }\end{array}$ \\
\hline 1 & $\begin{array}{l}\text { Belimbing } \\
\text { wuluh } \\
\text { (Averrhoa } \\
\text { bilimbi L.) }\end{array}$ & Ceneneng & 2 & Direbus \\
\hline 2 & $\begin{array}{l}\text { Daun kumis } \\
\text { kucing } \\
\text { (Orthosiphon } \\
\text { aristatus } \\
\text { (Blume) Miq.) }\end{array}$ & $\begin{array}{l}\text { Daung kumis } \\
\text { kucing }\end{array}$ & 5 & Direbus \\
\hline 3 & $\begin{array}{l}\text { Daun avokad } \\
\text { (Persea } \\
\text { americana } \\
\text { Mill) }\end{array}$ & $\begin{array}{l}\text { Daung } \\
\text { apoka' }\end{array}$ & 17 & Direbus \\
\hline 4 & $\begin{array}{l}\text { Daun pepaya ( } \\
\text { Carica } \\
\text { papaya L.) }\end{array}$ & $\begin{array}{l}\text { Daung } \\
\text { keniki }\end{array}$ & 6 & Direbus \\
\hline 5 & $\begin{array}{l}\text { Buah } \\
\text { mengkudu } \\
\text { (Morinda } \\
\text { citrifolia } \mathrm{L} \text { ) }\end{array}$ & $\begin{array}{c}\text { Buah } \\
\text { mengkudu }\end{array}$ & 7 & Diparut \\
\hline 6 & $\begin{array}{l}\text { Bawang putih } \\
\text { (Aliium } \\
\text { sativum } \mathrm{L})\end{array}$ & Lasuna pute & 3 & Dimasak \\
\hline 7 & $\begin{array}{l}\text { Daun ubi jalar } \\
\text { (Ipomeae } \\
\text { batatas L.) }\end{array}$ & $\begin{array}{l}\text { Dauug lame } \\
\text { kandora' }\end{array}$ & 1 & Direbus \\
\hline 8 & $\begin{array}{l}\text { Daun pegagan } \\
\text { (Centella } \\
\text { asiatica) }\end{array}$ & Daun tungke & 3 & Direbus \\
\hline 9 & $\begin{array}{l}\text { Labu siam ( } \\
\text { Sechium } \\
\text { edule) }\end{array}$ & Lawo pute & 2 & Diparut \\
\hline 10 & $\begin{array}{l}\text { Daun Gaharu } \\
\text { (Aquilaria } \\
\text { moluccensis) }\end{array}$ & $\begin{array}{l}\text { Daung } \\
\text { gaharu }\end{array}$ & 1 & Direbus \\
\hline 11 & $\begin{array}{l}\text { Ketimun } \\
\text { (Cucumis } \\
\text { sativa } \mathrm{L} .)\end{array}$ & Bonte & 5 & Diparut \\
\hline 12 & $\begin{array}{l}\text { Daun Kersen } \\
\text { (Muntingia } \\
\text { calabura L.) }\end{array}$ & $\begin{array}{l}\text { Daung } \\
\text { kerseng }\end{array}$ & 14 & Direbus \\
\hline 13 & $\begin{array}{l}\text { Kelapa muda } \\
\text { (Cocos } \\
\text { nucifera L.) }\end{array}$ & Kaluku lolo & 2 & Direbus \\
\hline
\end{tabular}

\begin{tabular}{|c|c|c|c|c|}
\hline 14 & $\begin{array}{l}\text { Daun srikaya } \\
\text { (Annona } \\
\text { muricata L.) }\end{array}$ & $\begin{array}{l}\text { Daung } \\
\text { sirikaya }\end{array}$ & 4 & Direbus \\
\hline 15 & $\begin{array}{l}\text { Daun tapak } \\
\text { darah } \\
\text { (Catharanthus } \\
\text { roseus) }\end{array}$ & Daung rara & 2 & Direbus \\
\hline 16 & $\begin{array}{l}\text { Daun } \\
\text { sambung } \\
\text { nyawa } \\
\text { (Gynura } \\
\text { procumbens) }\end{array}$ & Dapo’ & 1 & Direbus \\
\hline
\end{tabular}

Sumber : Data Primer, 2018

Dari Tabel IV dapat dilihat dari 73 orang responden ternyata terdapat responden yang menggunakan lebih dari satu jenis tanaman obat, ada 16 jenis tanaman yang pernah dikonsumsi masyarakat yaitu, 2 orang menggunakan buah belimbing wuluh, 5 orang menggunakan daun kumis kucing, 17 orang menggunkan daun avokad, 6 orang menggunakan daun pepaya, 7 orang menggunakan buah mengkudu, 3 orang menggunakan bawang putih, 1 orang menggunakan daun ubi jalar, 3 orang menggunakan daun pegagan, 2 orang menggunakan labu siam, 1 orang menggunakan daun gaharu, 5 orang menggunakan ketimun, 14 orang menggunaan daun kersen, 2 orang menggunakan air kelapa muda, 4 orang menggunakan daun serikaya, 2 orang menggunakan daun tapak dara, 1 orang menggunakan daun sambung nyawa.

Tabel V Daftar jenis tanaman dan metode pengolahan yang digunakan sebagai obat antidiabetes oleh masyarakat Desa Kambuno Kecamatan Bulukumpa Kabupaten Bulukumba

\begin{tabular}{|c|c|c|c|c|}
\hline No & $\begin{array}{c}\text { Nama } \\
\text { Tumbuhan }\end{array}$ & $\begin{array}{c}\text { Nama } \\
\text { Asal }\end{array}$ & $\begin{array}{c}\text { Frekuensi } \\
\text { Penggunaan }\end{array}$ & $\begin{array}{c}\text { Metode } \\
\text { Pengolahan }\end{array}$ \\
\hline 1 & $\begin{array}{l}\text { Mahkota dewa } \\
\text { (Phaleria } \\
\text { macrocarpa) }\end{array}$ & $\begin{array}{c}\text { Mahkota } \\
\text { dewa }\end{array}$ & 18 & Direbus \\
\hline 2 & $\begin{array}{l}\text { Buah } \\
\text { mengkudu } \\
\text { (Morinda } \\
\text { citrifolia } \mathrm{L})\end{array}$ & $\begin{array}{c}\text { Buah } \\
\text { mengku } \\
\text { du }\end{array}$ & 4 & Diparut \\
\hline 3 & $\begin{array}{l}\text { Daun kelor } \\
\text { (Moringa } \\
\text { oleifera) }\end{array}$ & $\begin{array}{l}\text { Daung } \\
\text { tiloro }\end{array}$ & 3 & Direbus \\
\hline 4 & $\begin{array}{l}\text { Daun serikaya } \\
\text { (Annona } \\
\text { muricata L.) }\end{array}$ & $\begin{array}{c}\text { Daung } \\
\text { serikaya }\end{array}$ & 9 & Direbus \\
\hline 5 & $\begin{array}{l}\text { Bawang merah } \\
\text { (Allium cepa } \\
\text { L.) }\end{array}$ & $\begin{array}{l}\text { Lasuna } \\
\text { cella' }\end{array}$ & 1 & Dimasak \\
\hline 6 & $\begin{array}{l}\text { Daun sambiloto } \\
\text { (Andrographis } \\
\text { paniculata } \\
\text { Ness) }\end{array}$ & $\begin{array}{l}\text { Daung } \\
\text { pai' pai' }\end{array}$ & 3 & Direbus \\
\hline 7 & $\begin{array}{l}\text { Daun Salam } \\
\text { (SyzgiumPolyan } \\
\text { thum) }\end{array}$ & $\begin{array}{l}\text { Daung } \\
\text { salang }\end{array}$ & 8 & Direbus \\
\hline
\end{tabular}




\begin{tabular}{clccc}
\hline $\mathbf{8}$ & $\begin{array}{l}\text { Peria } \\
\text { (Momordica } \\
\text { Charantica } \\
\text { Descourt. }\end{array}$ & Paria & 2 & Direbus \\
\hline $\mathbf{9}$ & $\begin{array}{l}\text { Lidah Buaya } \\
\text { (Aloe Vera L.) }\end{array}$ & $\begin{array}{c}\text { Lilla } \\
\text { Buaya }\end{array}$ & 2 & Direbus \\
\hline $\mathbf{1 0}$ & $\begin{array}{l}\text { Daun mangga } \\
\text { (Mangifera } \\
\text { indica) }\end{array}$ & $\begin{array}{c}\text { Daung } \\
\text { pao' }\end{array}$ & 3 & Direbus \\
\hline $\mathbf{1 1}$ & $\begin{array}{l}\text { Kayu manis } \\
\text { (Cinnamomum } \\
\text { verum })\end{array}$ & $\begin{array}{c}\text { Lenga } \\
\text { cenning }\end{array}$ & 5 & Direndam \\
\hline
\end{tabular}

Sumber : Data Primer, 2018

Dari Tabel V diatas dapat dilihat dari 73 orang responden ternyata ada beberapa responden yang tidak mengetahui tanaman obat untuk penderita diabetes melitus dan ada pula yang menggunakan lebih dari satu jenis tanaman obat, ada 11 jenis tanaman yang pernah dikonsumsi masyarakat yaitu, 18 orang menggunakan mahkota dewa, 4 orang menggunakan mengkudu, 3 orang menggunakan daun kelor, 9 orang menggunakan daun serikaya, 1 orang menggunakan bawang merah, 3 orang menggunakan daun sambiloto, 8 orang menggunakan daun salam, 2 orang menggunakan buah peria, 2 orang menggunakan lidah buaya, 3 orang menggunakan daun mangga, 5 orang menggunakan kayu manis.

Tabel VI. Daftar jenis tanaman obat dan pemakaiannya yang digunakan sebagai obat antihipertensi oleh masyarakat Desa Kambuno Kacamatan Bulukumpa Kabupaten Bulukumba

\begin{tabular}{|c|c|c|c|}
\hline No. & $\begin{array}{c}\text { Nama } \\
\text { Tanaman } \\
\text { Obat }\end{array}$ & $\begin{array}{c}\text { Bagian } \\
\text { Tanaman } \\
\text { Yang Diolah }\end{array}$ & Pemakaian \\
\hline 1 & $\begin{array}{l}\text { Belimbing } \\
\text { wuluh } \\
\text { (Averrhoa } \\
\text { bilimbi L.) }\end{array}$ & Buah & Tunggal \\
\hline 2 & $\begin{array}{l}\text { Daun kumis } \\
\text { kucing } \\
\text { (Orthosiphon } \\
\text { aristatus } \\
\text { (Blume) Miq.) }\end{array}$ & Daun & Kombinasi \\
\hline 3 & $\begin{array}{l}\text { Daun alpukat } \\
\text { (Persea } \\
\text { americana } \\
\text { Mill) }\end{array}$ & Daun & Kombinasi \\
\hline 4 & $\begin{array}{l}\text { Daun pepaya } \\
\text { (Carica } \\
\text { papaya } \mathrm{L.} \text {.) }\end{array}$ & Daun & Tunggal \\
\hline 5 & $\begin{array}{l}\text { Buah } \\
\text { mengkudu } \\
\text { (Morinda } \\
\text { citrifolia } \mathrm{L} \text { ) }\end{array}$ & Buah & Tunggal \\
\hline 6 & $\begin{array}{l}\text { Bawang putih } \\
\text { (Aliium } \\
\text { sativum } \mathrm{L} \text { ) }\end{array}$ & Buah & Tunggal \\
\hline 7 & $\begin{array}{l}\text { Daun ubi jalar } \\
\text { (Ipomeae }\end{array}$ & Daun & Tunggal \\
\hline
\end{tabular}

\begin{tabular}{|c|c|c|c|}
\hline & batatas L.) & & \\
\hline 8 & $\begin{array}{l}\text { Daun pegagan } \\
\text { (Centella } \\
\text { asiatic) }\end{array}$ & Daun & Tunggal \\
\hline 9 & $\begin{array}{l}\text { Labu siam } \\
\text { (Sechium } \\
\text { edule) }\end{array}$ & Buah & Tunggal \\
\hline 10 & $\begin{array}{l}\text { Daun Gaharu } \\
\text { (Aquilaria } \\
\text { moluccensis) }\end{array}$ & Daun & Tunggal \\
\hline 11 & $\begin{array}{l}\text { Ketimun } \\
\text { (Cucumis } \\
\text { sativa } \text { L.) }\end{array}$ & Buah & Tunggal \\
\hline 12 & $\begin{array}{l}\text { Daun Kersen } \\
\text { (Muntingia } \\
\text { calabura L.) }\end{array}$ & Daun & Kombinasi \\
\hline 13 & $\begin{array}{l}\text { Kelapa } \\
\text { muda(Cocos } \\
\text { nucifera L. })\end{array}$ & Air & Tunggal \\
\hline 14 & $\begin{array}{l}\text { Daun srikaya } \\
\text { (Annona } \\
\text { muricata L.) }\end{array}$ & Daun & Tunggal \\
\hline 15 & $\begin{array}{l}\text { Daun tapak } \\
\text { darah } \\
\text { (Catharanthus } \\
\text { roseus) }\end{array}$ & Daun & Tunggal \\
\hline 16 & $\begin{array}{l}\text { Daun } \\
\text { sambung } \\
\text { nyawa } \\
\text { (Gynura } \\
\text { procumbens) }\end{array}$ & Daun & Tunggal \\
\hline
\end{tabular}

\section{Sumber : Data Primer, 2018}

Dari tabel VI diperoleh data bagian tanaman obat yang digunakan untuk mengobati penyakit hipertensi adalah daun dengan frekuensi 10, buah dengan frekuensi 5, air dengan frekuensi 1 . Pemakaian yag digunakan adalah tunggal dengan frekuensi 13 dan pemakaian kombinasi dengan frekuensi 3 .

Tabel VII. Daftar jenis tanaman obat dan pemakaiannya yang digunakan sebagai obat antidiabetes oleh masyarakat Desa Kambuno Kacamatan Bulukumpa Kabupaten Bulukumba

\begin{tabular}{cccc}
\hline No. & $\begin{array}{c}\text { Nama Tanaman } \\
\text { Obat }\end{array}$ & $\begin{array}{c}\text { Bagian Tanaman } \\
\text { Yang Diolah }\end{array}$ & Pemakaian \\
\hline $\mathbf{1}$ & $\begin{array}{c}\text { Mahkota dewa } \\
\text { (Phaleria } \\
\text { macrocarpa) }\end{array}$ & Buah & Kombinasi \\
\hline $\mathbf{2}$ & $\begin{array}{c}\text { Buah mengkudu } \\
\text { (Morinda } \\
\text { citrifolia } \text { L) }\end{array}$ & Buah & Kombinasi \\
\hline $\mathbf{3}$ & $\begin{array}{c}\text { Daun kelor } \\
\text { (Moringa } \\
\text { oleifera })\end{array}$ & Daun & Kombinasi \\
\hline $\mathbf{4}$ & $\begin{array}{c}\text { Daun sirsak } \\
(\text { Annona } \\
\text { muricata } \text { L. })\end{array}$ & Daun & Kombinasi \\
\hline $\mathbf{5}$ & $\begin{array}{c}\text { Bawang merah } \\
\text { (Allium } \text { cepa } \text { L. })\end{array}$ & Buah & Kombinasi \\
\hline $\mathbf{6}$ & $\begin{array}{c}\text { Daun sambiloto } \\
\text { (Andrographis } \\
\text { paniculata } \text { Ness })\end{array}$ & Daun & Kombinasi \\
\hline $\mathbf{7}$ & $\begin{array}{c}\text { Daun Salam } \\
\text { (Syzgium }\end{array}$ & Daun & \\
\hline
\end{tabular}




\section{Jurnal Farmasi Sandi Karsa (JFS)}

https://jurnal.farmasisandikarsa.ac.id/ojs/index.php/JFS/index

polyanthum)

\begin{tabular}{ccll}
\hline $\mathbf{8}$ & $\begin{array}{c}\text { Peria } \\
\text { (Momordica } \\
\text { Charantica } \\
\text { Descourt. }\end{array}$ & Buah & Kombinasi \\
\hline $\mathbf{9}$ & $\begin{array}{c}\text { Lidah Buaya } \\
\text { (Aloe Vera L.) }\end{array}$ & Batang & Kombinasi \\
\hline $\mathbf{1 0}$ & $\begin{array}{c}\text { Daun mangga } \\
\text { (Mangifera } \\
\text { indica })\end{array}$ & Daun & Kombinasi \\
\hline $\mathbf{1 1}$ & $\begin{array}{c}\text { Kayu manis } \\
\text { (Cinnamomum } \\
\text { verum })\end{array}$ & Kayu & Kombinasi \\
\hline
\end{tabular}

Sumber : Data Primer, 2018

Dari tabel VII diperoleh data bagian tanaman obat yang digunakan untuk mengobati penyakit diabetes melitus adalah daun dengan frekuensi 5, buah dengan frekuensi 4, kemudian batang dengan frekuensi 1, dan kayu dengan frekuensi 1. Pemakaian yang digunakan adalah Kombinasi dengan frekuensi 11.

\section{B. Pembahasan}

Penelitian yang dilakukan di Desa Kambuno Kacamatan Bulukumpa Kabupaten Bulukumba telah dilaksanakan pada bulan Mei - Juni 2018 dengan jumlah responden sebanyak 73 orang, dimana responden yang menderita hipertensi sebanyak 41 responden, yang menderita diabetes melitus sebanyak 13 responden dan yang menderita hipertensi dan diabetes melitus adalah 19 responden. Diperoleh 16 jenis tanaman obat yang terdiri dari 15 famili yang digunakan sebagai obat antihipertensi dan 13 jenis tanaman obat yang terdiri dari 12 famili yang digunakan sebagai obat antidiabetes, dan yang memiliki famili yang sama hanya 1 jenis yaitu bawang merah dan bawang putih.

Tanaman obat yang paling banyak digunakan oleh masyarakat Desa Kambuno Kecamatan Bulukumpa Kabupaten Bulukumba untuk mengobati penyakit hipertensi adalah daun alpukat dan daun kersen. Daun alpukat dengan nama latin Perseaamericana Mill adalah tanaman obat yang paling banyak digunakan oleh masyaraat tersebut sebagai obat anti hipertensi atau penurun tekanan darah tinggi. Mereka meyakini bahwa tumbuhan tersebut ampuh untuk menurunkan tekanan darah berdasarkan dari pengalaman-pengalaman sebelumnya. Daun alpukat sudah dikenal memiliki banyak khasiat untuk kesehatan tubuh terutama untuk mengobati penyakit hipertensi. Masyarakat Desa Kambuno mengolah daun alpukat tersebut dengan cara direbus, sebelum direbus daun alpukat terlebih dahulu dicuci lalu direbus dengan 2 gelas air, tunggu hingga tersisa 1 gelas kemudian saring, minumlah secara rutin sekali dalam sehari, Cara penggunaannya yaitu Kombinasiada campuran dari obat modern atau obat dokter. Daun alpukat ini kaya akan kandungan nutrisi yang sangat baik untuk tubuh. Daun alpukat memiliki kandungan flavonoid yang berfungsi mengendalikan tekanan darah.

Daun kersen dengan nama latin Muntingiacalabura L. juga merupakan salah satu tanaman yang paling banyak digunakan oleh masyarakat Desa Ajubissue sebagai obat anti hipertensi karena daun kersen juga telah lama diakui masyarakat Desa Ajubissue sebagai obat penurun tekanan darah tiggi. Daun kersen diolah dengan cara direbus sebelum direbus daun kersen dicuci terlebih dahulu lalu direbus dengan 3 gelas air, tunggu hingga tersisa kurang lebih 2 gelas kemudian disaring, minumlah 2 kali dalam sehari, untuk cara yang lebih praktis dan tahan lama daun kersen dapat dikeringkan terlebih dahulu misalnya dijemur hingga benar benar kering, setelah itu daun kersen yang telah kering diseduh dengan air panas yang diminum setiap pagi dan malam 1 gelas. Cara penggunaannyayaitukombinasiada campuran dari obat modern atau obat dokter. Daun kersen memiliki kandungan senyawa flavonoid, tannin, triterpenoid, saponin, dan polifenol. Flavonoid terdapat dalam daun kersen yang dapat berfungsi sebagai anti hipertensi.

Tanaman obat yang paling banyak digunakan oleh masyarakat Desa Kambuno untuk mengobati penyakit diabetes melitus adalah mahkota dewa dan daun sirsak. Mereka meyakini bahwa tumbuhan tersebut ampuh menurunkan gula darah berdasarkan dari pengalaman-pengalaman sebelumnya. Mahkota dewa dengan nama latin Phaleriamacrocarpa adalah tanaman obat yang paling banyak digunakan oleh masyarakat Desa Kambuno sebagai obat anti diabetes. Buah Mahkota dewa sudah dikenal memiliki banyak khasiat untuk mengobati berbagai penyakit, khususnya diabetes melitus. Buah mahkota dewa berbentuk bundar agak kecil dan berwarna merah, sedangkan dagingnya berwarna putih dan daging buah inilah yang digunakan sebagaiobat diabetes melitus. Daging buah mahkota dewa mengandung senyawa golongan alkaloid, saponin, flavonoid dan saponin. Senyawa saponin inilah yang berkhasiat sebagai anti diabetes karena bersifat sebagai inhibitor (penghambat) Enzim a-glucosidse merupakan enzim yang berperan dalam mengubah karbohidrat menjadi glukosa. Dengan demikian, apabila enzim tersebut kita hambat kerjanya, maka kadar glukosa (gula) dalam darah akan menurun, sehingga menimbulkan efek hipoglikemik (kadar gula dalam darah menurun). Cara penggunaannya yaitu kombinasi ada campuran dari obat modern atau obat dokter. Untuk pengobatan diabetes melitus 
dengan cara direbus, sebelumnya sediakan 5 hingga 6 buah mahkota dewa yang telah dicuci bersih, kemudian bagian kulit dan bijinya dibuang, sedangkan daging buah diris tipis kemudian direbus dengan 3 gelas air, setelah itu sari daging buahnya disaring dan didinginkan diminum 3 kali sehari sebelum makan.

Daun sirsak dengan nama latin AnnonamuricataL. merupakan salah satu tanaman yang paling banyak digunakan oleh masyarakat Desa Ajubissue sebagai obat anti diabetes. Daun sirsak diolah dengan cara direbus, siapkan 10 sampai 15 lembar daun sirsak dan juga 3 gelas air, kemudian direbus hingga hanya tersisa 1 gelas, kemudian disaring diamkan sebentar hingga hangat kemudian diminum 2 kali dalam sehari . Sebaiknya daun sirsak yang digunakan tidak terlalu tua dan juga tidak terlalu muda agar kandungan senyawa yang ada didalam daun sirsak bisa dimanfaatkan dengan optimal. Cara penggunaannya yaitu kombinasi ada campuran dari obat modern atau obat dokter. Kandungan atau senyawa yang terdapat di dalam daun sirsak adalah lemak, vitamin B, vitamin $\mathrm{A}$, protein, fruktosa, kalsium, alkaloid, flavonoid, saponin, teroid dan astogenin. Kandungan-kandungan tersebutlah yang menjadi penurun gula darah agar tetap berada dalam kondisi yang stabil.

Sesuai hasil wawancara, masyarakat menggunakan dua pengobatan yaitu obat tradisional dan obat modern, masyarakat lebih banyak yang menggunakan obat tradisional dikarenakan mudah didapat, aman digunakan karena memiliki efek samping yang kecil dan penggunaannya mudah. Biasanya masyrakat mengkonsumsi tanaman obat tradisional 1 sampai 2 jam setelah mengkonsumsi obat sintetik kemudian mengkonsumsi tanaman obat, tetapi ada pula yang mengkonsusi tanaman obat tradisional tersebut setiap 2 hari sekali atau lebih. Hal ini dikarenakan tanaman obat bersifat mengikat zat dari obat sintetik, akibatnya efek obat menjadi tidak maksimal. Masyarakat mendapatkan tumbuhan di kebun karena biasanya banyak terdapat tumbuh-tumbuhan yang tumbuh liar di kebun masyarakat. Selain itu, ada pula yang sengaja menanam tanaman tetapi bukan untuk tujuan obat hipertensi dan diabetes melitus melainkan hanya untuk dikonsumsi buahnya. Selama ini masyarakat tidak pernah merasakan ada efek samping yang merugikan selama mengonsumsi tumbuhan obat, yang ada hanyalah manfaat yaitu menurunkan tekanan darah dan gula darah, tetapi perlu diingat pula bahwa peggunaan tanaman obat yang tidak sesuai dengan dosis dan kesalahan informasi dapat menimbulkan efek samping yang tidak diinginkan.

\section{PENUTUP}

\section{A. Kesimpulan}

Terdapat 16 jenis tanaman obat yang terdiri dari 15 famili yang digunakan sebagai obat anti hipertensi dan 13 jenis tanaman obat yang terdiri dari 13 famili yang digunakan sebagai obat anti diabetes oleh masyarakat di Desa Kambuno Kecamatan Bulukumpa Kabupaten Bulukumba.

Jenis tanaman obat yang paling sering digunakan oleh masyarakat Desa Kambuno Kecamatan Bulukumpa Kabupaten Bulukumba untuk mengobati penyakit hipertensi adalah daun alpukat dan daun kersen, sedangkan untuk mengobati penyakit diabetes melitus adalah mahkota dewa dan daun sirsak, metode pengolahan yang paling banyak digunakan adalah direbus.

\section{B. Saran}

Disarankan untuk dilaksanakan penelitian uji efek terhadap kandungan kimia dari tanaman obat yang paling banyak digunakan oleh masyarakat Desa Kambuno Kecamatan Bulukumpa Kabupaten Bulukumba.

Diharapkan kepada peneliti selanjutnya dapat menginventarisasikan tanaman obat tradisional yang terrdapat di daerah masigmasing agar dapat menambah pengetahuan tentang obat tradisional.

\section{DAFTAR PUSTAKA}

Bustan, M. N. 2007. Epidemologi Penyakit Tidak Menular. Rineka Cipta, Jakarta

Dalimarth, S. 2004. Atlas Tumbuhan obat Indonesia Jilid 1. Pustaka Bunda, Jakarta

Dalimarth, S. 2008. Atlas Tumbuhan obat Indonesia Jilid 5. Pustaka Bunda, Jakarta

Daswi, D. R., Dewi S TR, Nurhidaayah. 2016. Inventarisasi Tanaman Obat Yang Digunakan Sebagai obat Hipertensi Di desa Gantarang Kecamatan Sinjai Tengah Kabupaten sinjai. Farmasi Poltekkes Kemenkes Makassar, Makassar

Dinas Kesehatan Provinsi Sulawesi Selatan. 2016. Profil Kesehatan Kota Makassar Tahun 2015, Makassar.

Gunawan, G.S. 2007. Farmakologi dan terapi edisi 5. Departemen Farmakologi dan Terapeutik FKUI, Jakarta 
Katno, P.S. 2013. Tingkat Manfaat dan Keamanan Tanaman Obat dan Obat Tradisional. Balai Penelitian Obat Tawangmangu, Fakultas Farmasi Universitas Gajah Mada, Yogykarta

Keputusan Mentri Kesehatan Nomor 1076/ MENKES/ VII/ 2003 tentang Penyelenggaraan Pengobatan Tradisional. Departemen Kesehatan RI, Jakarta

Lingga, D.A, Lestari F, Arisandy D.A. 2016. Inventarisasi Tumbuhan Obat di Kecamatan Lubuklinggau Utara II. Lubuklinggau, Jakarta

Notoatmodjo, S. 2010. Metodologi Penelitian Kesehatan. Rineka Cipta, Jakarta

Riset Kesehatan Dasar Laporan Provinsi Sulawesi Selatan. 2007. Badan Penelitian Dan Pengembangan Kesehatan, Departemen Kesehatan RI, Jakarta

Supardi, S.S. 2014. Metodologi Penelitian Untuk Mahasiswa Farmasi. Trans Indo Media, Jakarta

Surat Keputusan Mentri Kesehatan Nomor 149/SK//Menkes/IV//1978 tentag Definisi Tanaman obat. Departemen Kesehatan RI, Jakarta

Udarno, M.L dan Budi M.B. 2013. Warta Penelitian dan Pengembangan Tanaman Industri, Volume 19 Nomor 1, Pangrango, Jawa Barat

Riset Kesehatan Dasar. 2013. Badan Penelitian Dan Pengembangan Kesehatan, Departemen Kesehatan RI, Jakarta

Wibisono, Y dan Zikri A. 2017. Inventarisasi Jenis Tumbuhan yang berkhasiat sebagai Obat Pada Plot Konservasi Tumbuhan Obat di Samboja Kecamatan Samboja Kabupaten Kutai Kartanegara, Kehutanan, Fakultas Pertanian, Universitas 17 Agustus 1945 Samarinda, Samarinda

Sugiama, A.G. 2013. Manajemen Aset Pariwisata. Guardaya Intimarta, Bandung

World Health Organization Global. 2012. [diakses 23 April 2018].

http://www.who.int/gho/countries/idn.pdf?ua=1
Wirawan, I Gusti Putu Indra. 2015. Phaleria macrocarpa as antihypertension. Faculty of Medicine; Lampung 